\title{
ANALISIS TINGKAT DENGUNG PADA RUANG SERBAGUNA (Studi Kasus Gedung Guru Jakarta)
}

\author{
Syahida Wafa ${ }^{1}$, Novita ${ }^{2}$, Atie Ernawati ${ }^{3}$, Ryan Hidayat ${ }^{4}$, M. Sega Sufia Purnama ${ }^{5}$ \\ ${ }^{1}$ Universitas Indraprasta PGRI, Program Studi Arsitektur \\ syahida_wafa@gmail.com \\ ${ }^{2}$ Universitas Indraprasta PGRI, Program Studi Arsitektur \\ novitav091@gmail.com \\ ${ }^{3}$ Universitas Indraprasta PGRI, Program Studi Arsitektur \\ atie.ernawati@unindra.ac.id \\ ${ }^{4}$ Universitas Indraprasta PGRI, Program Studi Arsitektur \\ ryansastra3@gmail.com \\ ${ }^{3}$ Universitas Indraprasta PGRI, Program Studi Arsitektur \\ ages125@gmail.com
}

\begin{abstract}
Meeting activities in the multipurpose building can run well if the voice of the speaker can be heard clearly into the ears of the audience (meeting members). One of the acoustic parameters that can be heard clearly in the room is the reverberation time. If the reverberation time is too long, the content of the conversation will be unclear because the sound source of the sound will take longer to reach the ear of the sound receiver. Therefore, the authors tried to analyze the level of reverberation in the multipurpose room. The purpose of this study was to determine the level of reverberation in the multipurpose room, a case study of the Jakarta teacher building. The research method used is a quantitative method, with the calculation of reverberation time (Buzz Time) with the Sabine formula method. Based on the reverberation time calculation that has been carried out by the researcher, the level of reverberation in the multipurpose hall of the Jakarta teacher building is 3.3 seconds, which does not meet the standard as a multipurpose auditorium space, namely 1.5 to 1.7 seconds.
\end{abstract}

Key Words: Analysis, Reverberation level, Teacher building

\begin{abstract}
Abstrak. Kegiatan rapat di Gedung serbaguna bisa berjalan dengan baik jika suara dari pembicara bisa terdengar dengan jelas ke telinga hadirin (anggota rapat). Salah satu parameter akustik agar pembicaraan dalam ruangan bisa jelas terdengar adalah waktu dengung (Reverberation Time). Jika waktu dengung terlalu panjang maka isi pembicaraan menjadi tidak jelas karena suara sumber bunyi akan semakin lama sampai ke telinga penerima bunyi. Oleh karena itu penulis mencoba meneliti analisis tingkat dengung di ruang serbaguna. Tujuan dalam penelitian ini untuk mengetahui tingkat dengung pada ruang serbaguna, studi kasus gedung guru Jakarta. Metode penelitian yang digunakan adalah metode kuantitatif, dengan perhitungan reverberation time ( Waktu Dengung) dengan metode rumus Sabine. Berdasarakan perhitungan waktu dengung yang telah dilakukan oleh peneliti, bahwa tingkat dengung ruang aula serbaguna gedung guru Jakarta sebesar 3,3 detik, tidak memenuhi standar sebagai ruang auditorium serbaguna yaitu dinatara 1,5 hingga 1,7 detik.
\end{abstract}

Kata Kunci : Analisis, Tingkat dengung, Gedung guru

\section{PENDAHULUAN}

Ruang serbaguna sering digunakan untuk berbagai keperluan seperti forum-forum rapat dan diskusi, seminar, pameran sampai pagelaran seni. Pada bangunan dan gedung fungsi ruang serbaguna dapat disesuakan berdasarkan peruntukan fungsi bangunan itu sendiri (Templeton, 2001). Beberapa contoh yaitu bangunan Masjid Agung Al-Muchlishin grogol yang fungsi ruang serbaguna tersebut digunakan sebagai tempat acara pernikahan. Lalu ada ruang serbaguna di SMAN 64 jakarta yang sering digunakan sebagai tempat pagelaran seni. Kemudian ada ruang serbaguna di gedung Yayasan Pembina Lembaga Pendidikan (YPLP) Persatuan Guru Republik Indonesia (PGRI) Jakarta yang berfungsi sebagai ruang ujian, rapat , seminar dan lain sebagainya. Berdasarkan ragam fungsi tersebut ruang serbaguna dapat dikatakan sebagai auditorium multifungsi atau sebaguna. 
Sehingga kegiatan-kegiatan yang dilakukan didalamnya membutuhkan tingkat kenyamanan akustik tertentu.(Akustik Ruang - Wikipedia Bahasa Indonesia, Ensiklopedia Bebas, n.d.)

Pada saat kegiatan di dalam ruang auditorium berlangsung banyak ketidaknyamanan yang dapat dirasakan seperti adanya gema, bising dari luar ruang yang masuk, penyebaran suara yang tidak merata, dan lain sebagainya. Berdasarkan pengalaman pribadi salah satu contoh ketidaknyamanan akustik yang terjadi ada diruang aula gedung Yayasan Pembina Lembaga Pendidikan (YPLP) Persatuan Guru Republik Indonesia (PGRI) Jakarta. Dimana pada saat mengikuti acara seminar dan Ujian Pengendalian Mutu (UPM) diruang tersebut dengung dan bising dari luar sangat terasa.

Dengung sendiri merupakan keadaan yang berlangsung terus menerus dan bersambung pada suara akibat dari pemantulan berkali-kali antara permukaan dalam ruangan (McMullan, 2007). Umumnya waktu dengung untuk auditorium serbaguna diambil pada nilai waktu dengung yang merupakan nilai kompromi antara fungsi musik dan fungsi pidato, yaitu rentang waktu dengung menengah (diantara 1,5 hingga 1,7 detik). (Sutanto, 2015)

\section{Dengung}

Dengung (reverberation) adalah keadaan yang berlangsung terus menerus dan bersambung pada suara akibat dari pemantulan berkali-kali antara permukaan dalam ruangan (McMullan, 2007). Penerima menerima bunyi secara langsung dan bunyi tersebut dipantulkan oleh permukaan dalam ruangan. Bunyi akan kehilangan energinya akibat pemantulan bunyi yang besarnya tergantung pada bentuk dan sifat penyerapan dari bidang permukaan. Pengurangan kerapatan energi bunyi akibat pemantulan bunyi tersebut merupakan fenomena waktu dengung. (McMullan, 2007)

Ruang akustik sebaiknya didesain benar benar tertutup secara fisik agar kualitas dan kuantitas suara yang terjadi didalamnya terjaga dengan baik. Apalagi pada umumnya ruang auditorium merupakan ruang yang tertutup dengan bidang - bidang pelingkup yang berfungsi membungkus sebuah ruangan dengan tujuan menjaga fungsi akustik ruang yang optimal.(Industri et al., 2010)

Berdasarkan jenis aktivitas yang dapat berlangsung di dalamnya, maka suatu auditorium dibedakan jenisnya menjadi: (Mediastika, 2005)

a) Auditorium untuk pertemuan, yaitu auditorium dengan aktivitas utama percakapan (speech) : seperti untuk seminar, konferensi, rapat besar, dan lain-lain.

b) Auditorium untuk pertunjukan seni, yaitu auditorium dengan aktivitas utama sajian kesenian, seperti seni musik, tari dan lain-lain. Secara akustik, jenis auditorium ini masih dapat dibedakan lagi menjadi auditorium yang menampung aktivitas musik saja dan yang menampung aktivitas musik sekaligus gerak.

c) Auditorium multifungsi, yaitu auditorium yang tidak dirancang secara khusus untuk fungsi percakapan atau musik, namun sengaja dirancang untuk berbagai keperluan tersebut, termasuk pameran produk, perhelatan pernikahan, ulangtahun, dan lain-lain.

\section{Reverberation Time (Waktu Dengung)}

Waktu dengung adalah jangka waktu yang dibutuhkan oleh suatu bunyi untuk turun tingkat kekerasan suaranya sebesar $60 \mathrm{~dB}$ sejak sumber suara dalam ruang akustik tersebut dihentikan/dimatikan. Besar dari Panjangnya waktu dengung adalah dalam detik. Waktu dengung ini dapat dihitung dengan menggunakan rumus sabine (diformulasikan oleh fisikawan Amerika bernama Wallace Clement Sabine) atau dapat diukur dengan menggunakan software computer. (Sutanto, 2015)

\section{Rumus sabine $\longrightarrow T_{R}=0,16\left(\mathrm{~V} / \sum \mathrm{S} \alpha\right) \mathrm{dtk}$}

Dengan :

$0,16=$ konstanta

$\mathrm{V} \quad=$ volume ruang $\left(\right.$ dalam $\mathrm{m}^{3}$ )

$\sum \mathrm{S} \alpha=$ penyerapan total pada frekuensi bunyi bersangkutan, sabin, biasanya dihitung berdasarkan frekuensi 125, 250, 500, 1000, dan $2000 \mathrm{~Hz}(500-1000 \mathrm{~Hz}$ umumnya dijadikan acuan untuk menghitung waktu dengung ruang). 
$\sum \mathrm{S} \alpha$ sering disingkat dengan a saja. (Satwiko, 2005)

Untuk memperpendek waktu dengung pada auditorium serbaguna / multifungsi, digunakan pelapis pelingkup ruang yang bersifat sangat menyerap (Ardianti Sabtalistia, 2020). Pada besaran waktu dengung 1 detik, artikulasi katakata dapat terdengar dengan jelas oleh audience sehingga cocok untuk ruang-ruang yang murni digunakan untuk fungsi pidato. Dan untuk meyesuaikan besaran waktu dengung sesuai fungsi ruang, pada beberapa jenis multi-purpose hall, sering kali digunakan bidang-bidang pelingkup ruang yang bias disetel/diatur (atau bahkan dengan menggunakan teknologi tertentu sehingga bidangbidang plafond dan dinding bias buka/ditutup/digeser secara otomatis) sehingga volume ruang dapat diubah-ubah secara fleksibel dan dapat memengaruhi besaran waktu dengungnya. (Sutanto, 2015)

\section{METODOLOGI}

Kegiatan penelitian ini akan dilaksanakan di aula serbaguna pada Gedung Guru Jakarta dengan waktu penelitian sekitar 2 bulan dari mulai survey tempat, analisa pada ruang, perhitungan tingkat dengung, menentukan material.

Metode yang digunakan dalam penelitian adalah metode kuantitatif, dengan perhitungan reverberation time ( Waktu Dengung) dengan metode rumus Sabine.

\section{HASIL DAN PEMBAHASAN Perhitungan Dimensi Ruang}

Perhitungan waktu dengung dilakukan dengan menghitung volume ruang dan luas dari masing-masing benda yang terdapat didalam ruang terlebih dahulu. Berikut layout ruang serbaguna di gedung Guru Jakarta.

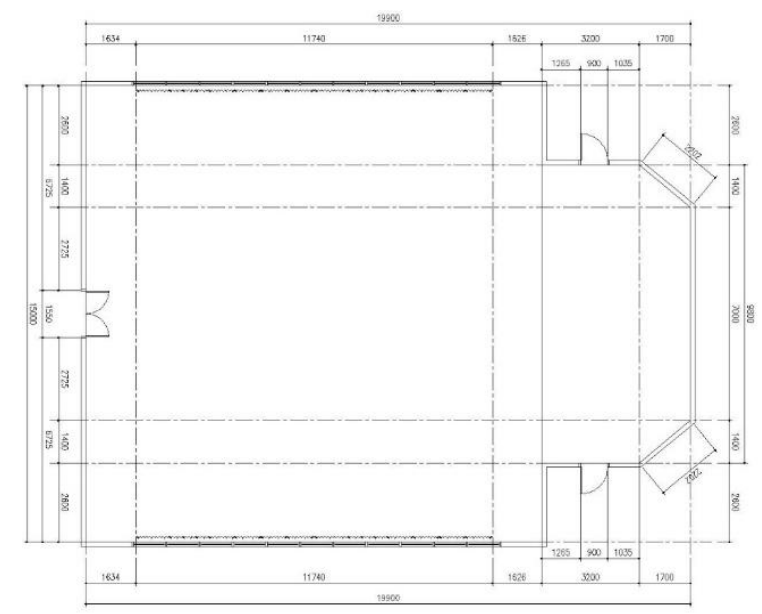

Gambar 1. Layout Ruang Serbaguna Gedung Guru

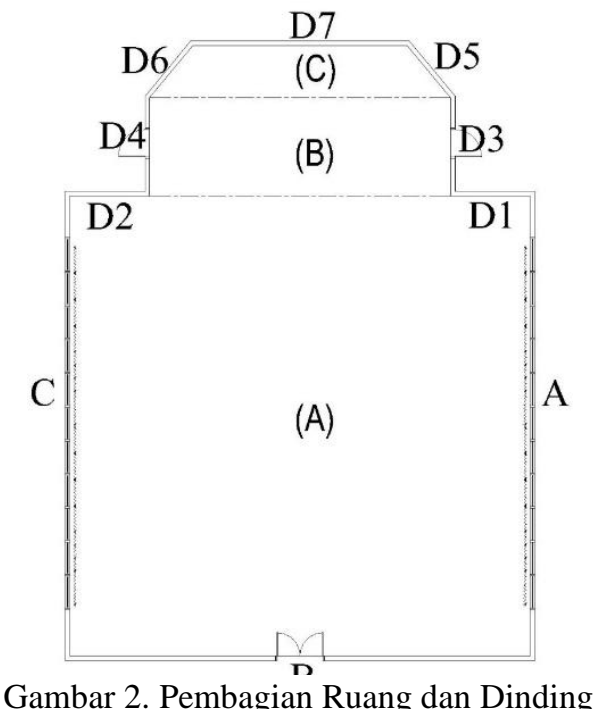

Gambar 2. Pembagian Ruang dan Dinding

$$
\begin{aligned}
& \text { Volume ruang: }(p \times l \times t) \\
& \begin{array}{l}
\text { (A) }=15 \mathrm{~m} \times 15 \mathrm{~m} \times 8 \mathrm{~m}=1800 \mathrm{~m}^{3} \\
\text { (B) }=9,8 \mathrm{~m} \times 3,2 \mathrm{~m} \times 7,6 \mathrm{~m}=238,4 \mathrm{~m}^{3} \\
\begin{array}{l}
\text { (C) }=\text { Luas trapezium } \times \mathrm{t} \\
\text { Luas alas trapesium } \\
2 \mathrm{a}=9,8 \mathrm{~m}-7 \mathrm{~m}=2,8 \mathrm{~m} \\
\mathrm{~A}=\frac{2,8 \mathrm{~m}}{2}=1,4 \mathrm{~m} \\
\mathrm{t}=\sqrt{\mathrm{c}^{2}-a^{2}} \\
=\sqrt{2,2 \mathrm{~m}^{2}-1,4 \mathrm{~m}^{2}} \\
=\sqrt{4,8 \mathrm{~m}-1,9 \mathrm{~m}} \\
=\sqrt{2,9}=1,7 \mathrm{~m} \\
=\frac{(9,8 \mathrm{~m}+7)}{2} \times 1,7 \mathrm{~m} \\
=\frac{16,8}{2} \times 1,7 \mathrm{~m} \\
=8,4 \mathrm{~m} \times 1,7 \mathrm{~m} \\
=14,28 \mathrm{~m}^{2}
\end{array} \\
\text { Volume ruang C } \\
=14,28 \mathrm{~m} \times 7,6 \mathrm{~m} \\
=108,5 \mathrm{~m}^{3}
\end{array}
\end{aligned}
$$

Jadi volume ruang :

$$
\begin{aligned}
(\mathrm{A})+(\mathrm{B})+(\mathrm{C}) & =1800 \mathrm{~m}^{3}+238,4 \mathrm{~m}^{3}+108,5 \\
m^{3} & =2146,9 \mathrm{~m}^{3}=>2147 \mathrm{~m}^{3}
\end{aligned}
$$

Luas Permukaan Atap :
(A) $=15 \mathrm{~m} \mathrm{x} 15 \mathrm{~m}=225 \mathrm{~m}^{2}$
(B) $=9,8 \mathrm{~m} \mathrm{x} \mathrm{3,2} \mathrm{m}=31,36 \mathrm{~m}^{2}$
(C) $=$ Luas alas trapezium $=14,28 \mathrm{~m}^{2}$

Luas permukaan atap :

$$
\begin{aligned}
& (\mathrm{A})+(\mathrm{B})+(\mathrm{C})=225 \mathrm{~m}^{2}+31,36 \mathrm{~m}^{2}+14,28 \mathrm{~m}^{2} \\
& =270,6 \mathrm{~m}^{2} \\
& \text { Skylight }=6 \mathrm{~m} \times 6 \mathrm{~m}=36 \mathrm{~m}^{2}
\end{aligned}
$$

LAKAR : Jurnal Arsitektur| Edisi Khusus Agustus (2020), 27-35 
Jadi, luas permukaan atap - Skylight $=270,6 \mathrm{~m}^{2}$ -

$36 m^{2}=234,64 m^{2}$

\section{Luas Permukaan Dinding :}

Dinding A $(p \times l)-$ luas tirai $(p \times l)$

$(15 \mathrm{~m} \times 8 \mathrm{~m})-(11,74 \mathrm{~m} \times 2 \mathrm{~m})=120 \mathrm{~m}^{2}-$ $23,48 m^{2}=96,52 m^{2}$

Dinding B $(p \times l)$ - panil kayu $(p \times l)$

$(15 \mathrm{~m} \times 8 \mathrm{~m})-(2,1 \mathrm{~m} \times 1,5 \mathrm{~m})=120 \mathrm{~m}^{2}-$ $3,15 \mathrm{~m}^{2}=116,85 \mathrm{~m}^{2}$

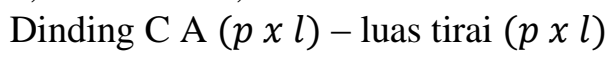

$(15 \mathrm{~m} \times 8 \mathrm{~m})-(11,74 \mathrm{~m} \times 2 \mathrm{~m})=120 \mathrm{~m}^{2}-$ $23,48 \mathrm{~m}^{2}=96,52 \mathrm{~m}^{2}$

Dinding $D_{1}, D_{2}\left(\begin{array}{lll}p & \times l\end{array}\right)$

$2,6 \mathrm{~m} \times 8 \mathrm{~m}=20,8 \mathrm{~m}^{2}$

Dinding $D_{3}, D_{4}(p \times l)$ - panil kayu $(p \times l)$

$(3,2 \mathrm{~m} \times 7,6 \mathrm{~m})-(2,1 \mathrm{mx} 0,9 \mathrm{~m})=24,32 \mathrm{~m}^{2}$ $1,8 \mathrm{~m}^{2}=22,52 \mathrm{~m}^{2}$

Dinding $D_{5}, D_{6}(p \times l)$

$2,2 \mathrm{~m} \times 7,6 \mathrm{~m}=16,72 \mathrm{~m}^{2}$

Dinding $D_{7}(p \times l)$

$7 \mathrm{mx} 7,6 \mathrm{~m}=53,2 \mathrm{~m}^{2}$

Luas Permukaan Lantai :

(A) $=15 \mathrm{~m} \mathrm{x} 15 \mathrm{~m}=225 \mathrm{~m}^{2}$

(B) $=9,8 \mathrm{~m} \mathrm{x} \mathrm{3,2} \mathrm{m}=31,36 \mathrm{~m}^{2}$

(C) $=$ Luas alas trapezium $=14,28 \mathrm{~m}^{2}$

Luas permukaan lantai :

(A) $+(\mathrm{B})+(\mathrm{C})=225 \mathrm{~m}^{2}+31,36 \mathrm{~m}^{2}+14,28 \mathrm{~m}^{2}$ $=270,6 \mathrm{~m}^{2}$ 


\section{Perhitungan Tingkat Dengung}

Setelah mengetahui volume ruang dan luas dari masing-masing benda yang ada didalam ruang, selanjutnya adalah menghitung koefisiensi serap ruang aula dimana data koefisiensi serap masing-masing partisi serta luasan partisinya ditunjukkan oleh table 1 di bawah ini:

Tabel 1. Data pengukuran luas masing-masing elemen beserta koefisiensi serap masing-masing bahan / materialnya

\begin{tabular}{|l|l|c|c|c|}
\hline \multirow{2}{*}{ ELEMEN } & \multicolumn{1}{|c|}{ BAHAN } & $\begin{array}{c}\text { KOEFISIEN } \\
\text { SERAPAN, } \propto 1000\end{array}$ & $\begin{array}{c}\text { LUAS, } \\
(\mathrm{m})\end{array}$ & S. \\
\hline \multirow{2}{*}{ Langit-langit } & Gipsum 1/2 & 0.04 & 234.64 & 9.3856 \\
\cline { 2 - 5 } & (Dibuka) & 1 & 36 & 36 \\
\hline \multirow{2}{*}{ Dinding (A) } & Plester pada batu bata & 0.03 & 96.52 & 2.8956 \\
\cline { 2 - 5 } & Tirai & 0.75 & 23.48 & 17.61 \\
\hline Dinding (B) & Plester pada batu bata & 0.03 & 116.85 & 3.5055 \\
\cline { 2 - 5 } & Panil Kayu & 0.5 & 3.15 & 1.575 \\
\hline \multirow{2}{*}{ Dinding (C) } & Plester pada batu bata & 0.03 & 96.52 & 2.8956 \\
\cline { 2 - 5 } & Tirai & 0.75 & 23.48 & 17.61 \\
\hline Dinding (D1) & Plester pada batu bata & 0.03 & 20.8 & 0.624 \\
\hline Dinding (D2) & Plester pada batu bata & 0.03 & 20.8 & 0.624 \\
\hline Dinding (D3) & Plester pada batu bata & 0.03 & 22.52 & 0.6756 \\
\cline { 2 - 5 } & Panil Kayu & 0.5 & 1.8 & 0.9 \\
\hline Dinding (D4) & Plester pada batu bata & 0.03 & 22.52 & 0.6756 \\
\cline { 2 - 5 } & Panil Kayu & 0.5 & 1.8 & 0.9 \\
\hline Dinding (D5) & Plester pada batu bata & 0.03 & 16.72 & 0.5016 \\
\hline Dinding (D6) & Plester pada batu bata & 0.03 & 16.72 & 0.5016 \\
\hline Dinding (D7) & Plester pada batu bata & 0.03 & 53.2 & 1.596 \\
\hline Lantai & Traso & 0.02 & 270.6 & 5.412 \\
\hline & & & Jumlah & 103.8877 \\
\hline
\end{tabular}

Dari data hasil perhitungan nilai koefisiensi serap ruang aula tersebut, maka langkah selanjutnya dapat dilakukan pengukuran nilai waktu dengung (Reverberation Time/RT) dengan menggunakan rumus sabine $T_{R}=0,16\left(\mathrm{~V} / \sum \mathrm{S} \alpha\right) \mathrm{dtk}$.

Dengan :

$0,16=$ konstanta

$\mathrm{V}=2147 m^{3}$

$\sum \mathrm{S} \alpha=103,88$

$$
\begin{aligned}
\mathrm{TR} & =0,16\left(\mathrm{~V} / \sum \mathrm{S} \alpha\right) \mathrm{dtk} . \\
& =0,16 \cdot\left(2147 \mathrm{~m}^{3} / 103,88\right) \text { detik } \\
& =0,16 \cdot 20,67 \\
& =3,3 \text { detik }
\end{aligned}
$$

Berdasarkan perhitungan diatas maka ruang aula pada Yayasan Pembina Lembaga Pendidikan (YPLP) Persatuan Guru Republik Indonesia (PGRI) Jakarta memiliki nilai tingkat dengung sebesar 3,3 detik. 


\section{Menemukan Elemen Ruang yang Tingkat Dengungnya Mendekati Standar}

Untuk menemukan bagian dari ruang aula pada Yayasan Pembina Lembaga Pendidikan (YPLP) Persatuan Guru Republik Indonesia (PGRI) Jakarta yang mendekati standart tingkat dengung, pertama dilakukan dengan mencari material yang dapat digunakan pada dinding, lantai dan langit-langit dengan koefisien daya serap cukup besar dalam ruangan tersebut. Material yang digunakan berupa rockwool dengan koefisien daya serap sebesar 0.45 pada frekuensi $1000 \mathrm{~Hz}$. Kemudian dihitung perelemen bagian ruang seperti berikut:

- Perhitungan pada Elemen Langit-langit $1000 \mathrm{~Hz}$

Bahan yang digunakan adalah rockwool dengan koefisien daya serap sebesar 0.45 pada frekuensi

Tabel 2. Data pengukuran luas masing-masing elemen beserta koefisiensi serap masing-masing bahan dengan material rockwool pada langit-langit.

\begin{tabular}{|l|l|c|c|c|}
\hline \multirow{2}{*}{ ELEMEN } & \multicolumn{1}{|c|}{ BAHAN } & $\begin{array}{c}\text { KOEFISIEN } \\
\text { SERAPAN, } \propto 1000\end{array}$ & $\begin{array}{c}\text { LUAS, } \\
(\mathrm{m})\end{array}$ & S. \\
\hline \multirow{2}{*}{ Langit-langit } & Rockwool & 0.45 & 234.64 & 105.588 \\
\cline { 2 - 5 } & (Dibuka) & 1 & 36 & 36 \\
\hline \multirow{2}{*}{ Dinding (A) } & Plester pada batu bata & 0.03 & 96.52 & 2.8956 \\
\cline { 2 - 5 } & Tirai & 0.75 & 23.48 & 17.61 \\
\hline Dinding (C) & Plester pada batu bata & 0.03 & 116.85 & 3.5055 \\
\cline { 2 - 5 } & Panil Kayu & 0.5 & 3.15 & 1.575 \\
\cline { 2 - 5 } & Tirai & 0.03 & 96.52 & 2.8956 \\
\hline Dinding (D1) & Plester pada batu bata & 0.75 & 23.48 & 17.61 \\
\hline Dinding (D2) & Plester pada batu bata & 0.03 & 20.8 & 0.624 \\
\hline Dinding (D3) & Plester pada batu bata & 0.03 & 20.8 & 0.624 \\
\cline { 2 - 5 } & Panil Kayu & 0.5 & 22.52 & 0.6756 \\
\hline Dinding (D4) & Plester pada batu bata & 0.03 & 1.8 & 0.9 \\
\cline { 2 - 5 } & Panil Kayu & 0.5 & 1.8 & 0.6756 \\
\hline Dinding (D5) & Plester pada batu bata & 0.03 & 16.72 & 0.9 \\
\hline Dinding (D6) & Plester pada batu bata & 0.03 & 16.72 & 0.5016 \\
\hline Dinding (D7) & Plester pada batu bata & 0.03 & 53.2 & 1.596 \\
\hline Lantai & Traso & 0.02 & 270.6 & 5.412 \\
\hline & & & Jumlah & 200.0901 \\
\hline
\end{tabular}

Dari data hasil perhitungan nilai koefisiensi serap ruang aula tersebut, maka langkah selanjutnya dapat dilakukan pengukuran nilai waktu dengung ( Reverberation Time / RT ) dengan menggunakan rumus sabine $T_{R}=0,16\left(\mathrm{~V} / \sum \mathrm{S} \alpha\right) \mathrm{dtk}$.

Dengan :

$$
\begin{aligned}
0,16 & =\text { konstanta } \\
\mathrm{V} & =2147 \mathrm{~m}^{3} \\
\sum \mathrm{S} \alpha & =200.0901
\end{aligned}
$$

$$
\begin{aligned}
\mathrm{TR} & =0,16\left(\mathrm{~V} / \sum \mathrm{S} \alpha\right) \mathrm{dtk} . \\
& =0,16 .\left(2147 \mathrm{~m}^{3} / 200,091\right) \text { detik }
\end{aligned}
$$




$$
\begin{aligned}
& =0,16 \cdot 10,73 \\
& =1,7 \text { detik }
\end{aligned}
$$

Berdasarkan perhitungan diatas maka elemen ruang berupa langit-langit bila ditretment mengunakan material rockwool menghasilkan tingkat dengung sebesar 1,7 detik.

- Perhitungan pada Elemen Dinding

Bahan yang digunakan adalah rockwool dengan koefisien daya serap sebesar 0.45 pada frekuensi $1000 \mathrm{~Hz}$.

Tabel 3. Data pengukuran luas masing-masing elemen beserta koefisiensi serap masing-masing bahan dengan material rockwool pada dinding.

\begin{tabular}{|l|l|c|c|c|}
\hline \multirow{2}{*}{ ELEMEN } & BAHAN & $\begin{array}{c}\text { KOEFISIEN } \\
\text { SERAPAN, } \propto 1000\end{array}$ & LUAS, S (m) & S. \\
\hline Langit-langit & Gipsum 1/2 & 0.04 & 234.64 & 9.3856 \\
\cline { 2 - 5 } & (Dibuka) & 1 & 36 & 36 \\
\hline \multirow{2}{*}{ Dinding (A) } & Rockwool & 0.45 & 96.52 & 43.434 \\
\cline { 2 - 5 } & Tirai & 0.75 & 23.48 & 17.61 \\
\hline Dinding (B) & Rockwool & 0.45 & 116.85 & 52.5825 \\
\cline { 2 - 5 } & Panil Kayu & 0.5 & 3.15 & 1.575 \\
\hline Dinding (C) & Rockwool & 0.45 & 96.52 & 43.434 \\
\cline { 2 - 5 } & Tirai & 0.75 & 23.48 & 17.61 \\
\hline Dinding (D1) & Rockwool & 0.45 & 20.8 & 9.36 \\
\hline Dinding (D2) & Rockwool & 0.45 & 20.8 & 9.36 \\
\hline Dinding (D3) & Rockwool & 0.45 & 22.52 & 10.134 \\
\cline { 2 - 5 } & Panil Kayu & 0.5 & 1.8 & 0.9 \\
\hline Dinding (D4) & Rockwool & 0.45 & 22.52 & 10.134 \\
\cline { 2 - 5 } & Panil Kayu & 0.5 & 1.8 & 0.9 \\
\hline Dinding (D5) & Rockwool & 0.45 & 16.72 & 7.524 \\
\hline Dinding (D6) & Rockwool & 0.45 & 16.72 & 7.524 \\
\hline Dinding (D7) & Rockwool & 0.45 & 53.2 & 23.94 \\
\hline Lantai & Traso & 0.02 & 270.6 & 5.412 \\
\hline & & & Jumlah & 306.8191 \\
\hline
\end{tabular}

Dari data hasil perhitungan nilai koefisiensi serap ruang aula tersebut, maka langkah selanjutnya dapat dilakukan pengukuran nilai waktu dengung ( Reverberation Time / RT ) dengan menggunakan rumus sabine $T_{R}=0,16\left(\mathrm{~V} / \sum \mathrm{S} \alpha\right) \mathrm{dtk}$.

$$
\begin{aligned}
0,16 & =\text { konstanta } \\
\mathrm{V} & =2147 \mathrm{~m}^{3} \\
\sum \mathrm{S} \alpha & =306.8191
\end{aligned}
$$

$$
\begin{aligned}
\mathrm{TR} & =0,16\left(\mathrm{~V} / \sum \mathrm{S} \alpha\right) \mathrm{dtk} . \\
& =0,16 \cdot(2147 \mathrm{M} 3 / 306,819) \text { detik } \\
& =0,16.6,99 \\
& =1,1 \text { detik }
\end{aligned}
$$


Berdasarkan perhitungan di atas maka elemen ruang berupa dinding bila ditretment mengunakan material rockwool menghasilkan tingkat dengung sebesar 1,1 detik.

- Perhitungan pada Elemen Lantai $1000 \mathrm{~Hz}$.

Bahan yang digunakan adalah rockwool dengan koefisien daya serap sebesar 0.45 pada frekuensi

Tabel 4. Data pengukuran luas masing-masing elemen beserta koefisiensi serap masing-masing bahan dengan material rockwool pada lantai

\begin{tabular}{|l|l|c|c|c|}
\hline \multirow{2}{*}{ ELEMEN } & \multicolumn{1}{|c|}{ BAHAN } & $\begin{array}{c}\text { KOEFISIEN } \\
\text { SERAPAN, } \propto 1000\end{array}$ & LUAS, S (m) & S. $\alpha$ \\
\hline \multirow{2}{*}{ Langit-langit } & Gipsum 1/2 & 0.04 & 234.64 & \\
& (Dibuka) & 1 & 36 & 9.3856 \\
\hline \multirow{2}{*}{ Dinding (A) } & Plester pada batu bata & 0.03 & 96.52 & 2.8956 \\
\cline { 2 - 5 } & Tirai & 0.75 & 23.48 & 17.61 \\
\hline Dinding (C) & Plester pada batu bata & 0.03 & 116.85 & 3.5055 \\
\cline { 2 - 5 } & Panil Kayu & 0.5 & 3.15 & 1.575 \\
\cline { 2 - 5 } & Plester pada batu bata & 0.03 & 96.52 & 2.8956 \\
\hline Dinding (D1) & Plester pada batu bata & 0.75 & 23.48 & 17.61 \\
\hline Dinding (D2) & Plester pada batu bata & 0.03 & 20.8 & 0.624 \\
\hline Dinding (D3) & Plester pada batu bata & 0.03 & 20.8 & 0.624 \\
\cline { 2 - 5 } & Panil Kayu & 0.5 & 22.52 & 0.6756 \\
\hline Dinding (D4) & Plester pada batu bata & 0.03 & 22.52 & 0.9 \\
\cline { 2 - 5 } & Panil Kayu & 0.5 & 1.8 & 0.6756 \\
\hline Dinding (D5) & Plester pada batu bata & 0.03 & 16.72 & 0.5016 \\
\hline Dinding (D6) & Plester pada batu bata & 0.03 & 16.72 & 0.5016 \\
\hline Dinding (D7) & Plester pada batu bata & 0.03 & 53.2 & 1.596 \\
\hline Lantai & Rockwool & 0.45 & 270.6 & 121.77 \\
\hline \multirow{2}{*}{} & & & Jumlah & 220.2457 \\
\hline
\end{tabular}

Dari data hasil perhitungan nilai koefisiensi serap ruang aula tersebut, maka langkah selanjutnya dapat dilakukan pengukuran nilai waktu dengung ( Reverberation Time / RT ) dengan menggunakan rumus sabine $T_{R}=0,16\left(\mathrm{~V} / \sum \mathrm{S} \alpha\right) \mathrm{dtk}$.

$$
\begin{aligned}
& \text { Dengan : } \\
& 0,16=\text { konstanta } \\
& \mathrm{V} \quad=2147 \mathrm{~m}^{3} \\
& \sum \mathrm{S} \alpha=220.2457
\end{aligned}
$$

$$
\begin{aligned}
\mathrm{TR} & =0,16\left(\mathrm{~V} / \sum \mathrm{S} \alpha\right) \mathrm{dtk} . \\
& =0,16 \cdot(2147 \mathrm{M} 3 / 220,245) \text { detik } \\
& =0,16.9,74 \\
& =1,5 \text { detik }
\end{aligned}
$$

Berdasarkan perhitungan diatas maka elemen ruang berupa lantai bila ditretment mengunakan material rockwool menghasilkan tingkat dengung sebesar 1,5 detik. 


\section{PENUTUP}

\section{Simpulan}

Berdasarakan perhitungan waktu dengung yang telah dilakukan oleh peneliti, bahwa tingkat dengung ruang aula serbaguna gedung guru Jakarta sebesar 3,3 detik, tidak memenuhi standar sebagai ruang auditorium serbaguna yaitu dinatara 1,5 hingga 1,7 detik. (Sutanto, 2015)

Berdasarkan perhitungan waktu dengung dengan pergantian bahan berupa rockwool perelemen dalam ruang, maka dinding menghasilkan tingkat dengung sebesar 1,1 detik merupakan elemen terbaik untuk di treatment agar tingkat dengung terminimalisir atau mendekati standar ruang auditorium serbaguna.

\section{Saran}

Arsitek yang membuat gedung, harus memerhatikan kedengungan, termasuk memilih bahan material, agar tidak terjadi dengung pada ruang. Semoga lebih banyak lagi penulis membuat penelitian tentang dengung.

\section{DAFTAR PUSTAKA}

Akustik ruang - Wikipedia bahasa Indonesia, ensiklopedia bebas. (n.d.). Retrieved July 15, 2020, from https://id.wikipedia.org/wiki/Akustik_ruang

Ardianti Sabtalistia, Y. (2020). Perbaikan Waktu Dengung Ruang Kuliah Dengan Optimalisasi Model Ruangan Dan Jenis Material. Pawon: Jurnal Arsitektur, 4(01), 65-76. https://doi.org/10.36040/pawon.v4i01.2347

Industri, F. T., Studi, P., \& Fisika, T. (2010). RUANGAN SERBA GUNA YANG TERLETAK DI JALAN ELANG NO 17 Disusun Oleh: Fakultas Teknologi Industri Program Studi Teknik Fisika Institut Teknologi Bandung Bandung. 17.

McMullan, R. (2007). Environmental Science in Building. Palgrave Macmillanm.

Mediastika, C. E. (2005). Akustika Bangunan. Erlangga.

Satwiko, P. (2005). Fisika Bangunan 1. Andi Publisher.

Sutanto, H. (2015). Prinsip-Prinsip Akustik Dalam Arsitektur. Kanisius.

Templeton, D. (2001). Detail Akustik. Erlangga. 